\title{
Promoter analysis of the rabbit POU5FI gene and its expression in preimplantation stage embryos Julianna Kobolak1 ${ }^{1}$, Katalin Kiss ${ }^{1,2}$, Zsuzsanna Polgar ${ }^{3}$, Solomon Mamo ${ }^{1,4}$, Claire Rogel-Gaillard ${ }^{5}$, Zsuzsanna Tancos ${ }^{1,6}$, Istvan Bock6,7, Arpad G Baji ${ }^{1}$, Krisztina Tar ${ }^{7}$, Melinda K Pirity ${ }^{7}$ and Andras Dinnyes*1,6
}

Address: ${ }^{1}$ Micromanipulation and Genetic Reprogramming Group, Agricultural Biotechnology Center, Szent-Györgyi A. u. 4 . H-2100 Gödöllő, Hungary, ${ }^{2}$ National Medical Center Cell Biology Department; Daróci u. 24. H-1113 Budapest, Hungary, ${ }^{3}$ Faculty of Natural Sciences, Constantine the Philosopher University, Slovakia, ${ }^{4}$ University College Dublin, Lyons Research Farm, Newcastle Co. Dublin, Ireland, ${ }^{5}$ INRA, UMR1313, Laboratoire de Génétique Animale et Biologie Intégrative, 78350 Jouy en Josas , France, ${ }^{6}$ Molecular Animal Biotechnology Laboratory, Szent Istvan University, Pater K. u. 1. H-2103 Gödöllő, Hungary and 7BioTalentum Ltd., Aulich Lajos u. 26. H-2100 Gödöllő, Hungary

Email: Julianna Kobolak - kobolak@abc.hu; Katalin Kiss - katalin.kiss@kkk.org.hu; Zsuzsanna Polgar - polgarzs@abc.hu; Solomon Mamo - msolomon@abc.hu; Claire Rogel-Gaillard - claire.rogel-gaillard@jouy.inra.fr; Zsuzsanna Tancos - tancoszs@abc.hu; Istvan Bock - istvan.bock@biotalentum.hu; Arpad GBaji - baji@abc.hu; Krisztina Tar - krisztina.tar@biotalentum.hu; Melinda K Pirity - melinda.pirity@biotalentum.hu; Andras Dinnyes* - andrasdinnyes@yahoo.com

* Corresponding author

Published: 4 September 2009

BMC Molecular Biology 2009, 10:88 doi:10.1186/147|-2199-10-88
Received: 12 December 2008

Accepted: 4 September 2009

This article is available from: http://www.biomedcentral.com//47/-2/99//0/88

(C) 2009 Kobolak et al; licensee BioMed Central Ltd.

This is an Open Access article distributed under the terms of the Creative Commons Attribution License (http://creativecommons.org/licenses/by/2.0), which permits unrestricted use, distribution, and reproduction in any medium, provided the original work is properly cited.

\begin{abstract}
Background: The POU5FI gene encodes the octamer-binding transcription factor-4 (Oct4). It is crucial in the regulation of pluripotency during embryonic development and widely used as molecular marker of embryonic stem cells (ESCs). The objective of this study was to identify and to analyse the promoter region of rabbit POU5FI gene; furthermore to examine its expression pattern in preimplantation stage rabbit embryos.

Results: The upstream region of rabbit POU5FI was subcloned sequenced and four highly conserved promoter regions (CRI-4) were identified. The highest degree of similarity on sequence level was found among the conserved domains between rabbit and human. Among the enhancers the proximal enhancer region (PE-IA) exhibited the highest degree of homology (96.4\%). Furthermore, the CR4 regulator domain containing the distal enhancer (DE-2A) was responsible for stem cell-specific expression. Also, BAC library screen revealed the existence of a processed pseudogene of rabbit POU5FI. The results of quantitative real-time PCR experiments showed that POU5FI mRNA was abundantly present in oocytes and zygotes, but it was gradually reduced until the activation of the embryonic genome, thereafter a continuous increase in POU5FI mRNA level was observed until blastocyst stage. By using the XYClone laser system the inner cell mass (ICM) and trophoblast portions of embryos were microdissected and examined separately and POU5FI mRNA was detected in both cell types.

Conclusion: In this study we provide a comparative sequence analysis of the regulatory region of rabbit POU5FI gene. Our data suggest that the POUSFI gene is strictly regulated during early mammalian development. We proposed that the well conserved CR4 region containing the DE-2A enhancer is responsible for the highly conserved ESC specific gene expression. Notably, we are the first to report that the rabbit POU5FI is not restricted to ICM cells only, but it is expressed in trophoblast cells as well. This information may be well applicable to investigate further the possible phylogenetic role and the regulation of POU5FI gene.
\end{abstract}




\section{Background}

The POU5F1 gene belongs to the POU (Pit-Oct-Unc) family of transcription factors, that encodes the octamer-binding transcription factor-4 (Oct4) [1]. In mouse, before the zygotic gene activation the active POU5F1 mRNA is present in the oocyte. The zygotic expression is activated around the 4-cell stage and later restricted to the pluripotent cells of the inner cell mass (ICM) and to the epiblast. Following implantation, the expression is down-regulated and limited to the primordial germ cells (PGC) but silenced in all somatic cells [2]. In vitro embryo studies in bovine, pig, rhesus monkey and in human have shown that the protein is present in the trophoblast cells of blastocyst stage embryos and it is not restricted to the pluripotent ICM cells [3-6]. In vitro, POU5F1 is highly expressed in human and mouse ESCs. These cells lose their pluripotency during differentiation, therefore the POU5F1 expression is diminished $[7,8]$.

The POU5F1 protein is among the core group of transcription factors that induces and controls stemness in ESCs. It sustains pluripotency through feed-forward and feedback transcriptional mechanism and it also plays a crucial role in the early mammalian development $[7,9]$.

The expression of POU5F1 is controlled by cis-regulatory elements, located 5 ' upstream from the initiation site of transcription $[2,10]$. The regulatory region of POU5F1 is highly conserved among species; and usually contains four conserved regions (CR) within the promoter. The TATA-less minimal promoter (MP) region is always located within the first conserved region (CR1) of the upstream sequence of the gene. This minimal promoter contains further primary regulatory elements, such as Sp1/Sp3, and hormone responsive element (HRE) binding sites. Reporter gene expression experiments in mouse with LacZ revealed that two elements, the proximal enhancer (PE) and the distal enhancer (DE) are essential in the cell-specific regulation of POU5F1. The proximal enhancer (PE) is located about $1.2 \mathrm{~kb}$ upstream, within conserved regions (CR2 and CR3) and is responsible for POU5F1 expression in embryonic ectoderm and mouse embryonal carcinoma (EC) cells. Finally, the distal enhancer (DE) located about $2 \mathrm{~kb}$ upstream, also within a conserved region (CR4) and drives the POU5F1 expression in the morula, ICM, ESC, embryonic germ (EG) and PGC cells of the mouse $[2,11,12]$.

Rabbit (Oryctolagus cuniculus) is a classical experimental animal model due to its physiological and immunological properties; it is preferentially used in pulmonary, cardiovascular and metabolic studies, as well as for antibody production and drug screening. In mouse, a wide range of genetic methods have been developed so far, and the successful application of the same technology in rabbits would be very desirable. Recent publications about gener- ating rabbit ESCs $[13,14]$ and successful somatic cell nuclear transfer (SCNT) experiments $[15,16]$ raise the possibility for increasing the use of rabbit model systems for wider applications.

Although the rabbit POU5F1 cDNA and the genomic DNA sequences were recently published [17], the isolation and the detailed characterisation of its regulatory region is still missing. Moreover, its expression during embryo preimplantation has not yet been well characterized [18]. This study for the first time describes isolation and sequencing of the rabbit orthologue of POU5F1 5' regulatory region and the identification of its phylogenetically conserved regions. We also examined the function of the individual truncated promoter regions using GFP reporter gene system. In addition we also examined the expression pattern of rabbit POU5F1 in individual preimplantation stage embryos using quantitative real-time PCR.

\section{Results}

\section{Isolation of the rabbit POU5FI upstream region}

Recently, the MHC region of rabbit was mapped [19] and partial POU5F1-like gene has been sequenced on BAC clones LBAB-841A3 and LBAB-85810. Based on multispecies sequence comparison (human, mouse and bovine POU5F1 genes), primers were designed for the conserved regions (oct4-435 and oct4-186, Table 1), and applied for PCR screens and further sequencing.

The sequenced $7.5 \mathrm{~kb}$ POU5F1-like region was confirmed as the rabbit's entire POU5F1 gene by multiple sequence comparison. Five highly conserved regions have been found, which perfectly matched with the well-characterized five exons of the reference sequences. The lengths of the sequences of these conserved, putative exonic regions were quite similar but not identical, indicating the existence of non-conserved intronic regions. The complete rabbit POU5F1 sequence is now referred to as EF194086 and mapped to the MHC region, 12q1.1 [17].

To confirm the coding sequence of POU5F1, RACE PCR was applied on blastocyst samples. The gene-specific inner primers were bound to the conserved region of the gene; the outer primers were annealed to the 5'UTR and the polyA tail. The expressed and coding region was found to be $1083 \mathrm{bp}$, which matched exactly with the previously predicted exons. The rabbit cDNA sequence was identical to human, mouse and bovine in $84 \%, 83 \%$ and $87 \%$, respectively. The cDNA sequence is now referred as EF062856[17].

\section{Sequence analysis of the rabbit POU5FI promoter region} Following confirmation of the POU5F1-like sequence as a rabbit coding sequence, the $2.2 \mathrm{~kb}$ fragment of the POU5F1 upstream region was sequenced and aligned to 
Table I: Primers used in BAC library screen, promoter analysis and real-time RT-PCRs

\begin{tabular}{|c|c|c|c|c|}
\hline Primer name & Primer (5'-3') sequence & Position & Primer size (bp) & $\operatorname{Tm}\left({ }^{\circ} \mathrm{C}\right)$ \\
\hline oct4-435-F & AGCTTAGCTTCAAGAACATG & +3665 & 20 & 60.0 \\
\hline oct4-435-R & AGGAGTACAGTGCAGTGAAG & +4704 & 20 & 60.0 \\
\hline oct4-I86-F & AGCAGAAACCCTCGTGCAGG & +3759 & 20 & 60.0 \\
\hline oct4-186-R & TCTGGCGCCGGTTACAGAAC & +4181 & 20 & 60.0 \\
\hline *oct4-pseudo-F & GCTAAACAGAAAGAAGTTTGCC & $*+420$ & 22 & 57.0 \\
\hline *oct4-pseudo-R & GAACAGTCACTGCTTGATCGTTT & $*+870$ & 23 & 58.1 \\
\hline oct4-cDNA-F & GCTCTACAGAAAGAACTCGAGCAG & +3640 & 24 & 57.9 \\
\hline oct4-cDNA-R & CGAGTACAGGGTAGCAAAGTGAG & +4869 & 23 & 60.0 \\
\hline CRI-ATGmut & TCTATGGGGGAAGGAGGGCG & +5 & 20 & 60.0 \\
\hline CRI & AGGCTGGTGGCATAAAACAC & -558 & 20 & 60.0 \\
\hline$C R 1+(C R 2+C R 3)$ & GCCAGACTAGAGCCCAACAG & -1585 & 20 & 60.0 \\
\hline$C R 1+(C R 2+C R 3)+C R 4$ & GGGAAATTGTGGAGGAGGAC & -2030 & 20 & 60.7 \\
\hline CR4 & TCTGTCTGCTTGGTGGTGTC & -1670 & 20 & 59.9 \\
\hline Rabbit-oct4-RT-F & CGAGTGAGAGGCAACTTGG & +4418 & 19 & 55.5 \\
\hline Rabbit-oct4-RT-R & CGGTTACAGAACCACACACG & +4730 & 20 & 56.1 \\
\hline *Rabbit-oct4p-RT-F & CTAAACAGAAAGAAGTTTGCC & $*+421$ & 21 & 53.7 \\
\hline *Rabbit-oct4p-RT-R & CGCAGCTTACACATGTACT & $*+594$ & 19 & 52.3 \\
\hline Mouse-oct4-RT-F & ATGCCGTGAAGTTGGAGAAG & +343 & 20 & 56.5 \\
\hline Mouse-oct4-RT-R & GGTCTGGCTGAACACCTTTC & +3309 & 20 & 55.9 \\
\hline
\end{tabular}

The initial ATG is signed as $+\mathrm{I}$, the positions show the genomic locations of the primer. F: forward, R: reverse * pseudogene-specific primers, the positions show the pseudogene location of the primers

its orthologues (Figure 1). The alignment proved the presence of four extensively conserved regions (CR1-4) and three enhancer regions in the rabbit POU5F1 5' upstream sequence. These CR regions are known to be the functional regions of the POU5F1 promoter in several species $[11,20]$. The different regions in rabbit showed extensive identity compared to the human, bovine, dog and to mouse sequences (Figure 1). In rabbit, the TATA-less minimal promoter (MP) that is located within the CR1 region, extends until $-221 \mathrm{bp}$, and contains both the overlapping binding sites of Sp1/Sp3 (-120/-110), the hormone responsive element $(-111 /-94)$ and three $\mathrm{G} / \mathrm{C}$ rich regions (Figure 1). The E-box sequence in rabbit (CACTTG), that plays a regulatory role in the control of transcription by binding basic helix-loop-helix (bHLH) transcription factors, is located within the proximal enhancer Region $1 \mathrm{~B}$ (PE-1B;-945/-940). The proximal enhancer Region 1B (968/-940) is localized within the CR2 region (-1023/824 ), while the proximal enhancer Region 1A (PE-1A;$1232 /-1192)$ is located outside of the CR2 region (-1480/ -1376). This PE-1A region exceptionally shows less similarity to all reference species. The CR3 region is localized upstream of PE-1A sequence. The distal enhancer region (DE-2A) is located within the CR4 region (-2450/-1901), last from -2025 to $-2004 \mathrm{bp}$. Transcription factor (TF) binding site, Oct4/Sox2 is located (-1977/-1962) in the distal enhancer, within the CR4 region. We have identified several G/C-rich motifs present in all of the five mammalian sequences; however the one near the PE-1A enhancer we found a CCCACCC motif present only in rabbit. This motif partially overlaps the CCCTCCC sequence. The schematic draw of organization of rabbit POU5F1 promoter region is shown in Figure 2.

Table 2 shows the pairwise comparison of the rabbit and four other mammalian POU5F1 regulatory regions. The analysis unambiguously revealed that the human has the closest potential evolutionary orthologue of the rabbit POU5F1 regulatory region. This is supported with the highest homology that could be observed between rabbit and human in all of the four conserved regions and in the PE-1B and DE-2A enhancers. The complete minimal promoter (0/-221 bp) and PE-1A enhancer were the two exceptional regions where the dog sequence showed the highest homology compared to the rabbit sequence (Table 2).

\section{Functional analysis of the promoter regions}

Four different reporter constructs were electroporated into mouse ESCs to test the functionality of the predicted conserved region in the POU5F1 promoter (Figure 3). The minimal (proximal) promoter (CR1), the proximal promoter with proximal enhancers (CR1+(CR2 and CR3), the proximal promoter with distal enhancer (CR1+CR4) and the entire promoter region $(\mathrm{CR} 1+(\mathrm{CR} 2$ and CR3)+CR4) were tested. The fluorescent activity of the minimal promoter (CR1) was very weak compared to the control ubiquitin promoter and to the basic auto-fluores- 


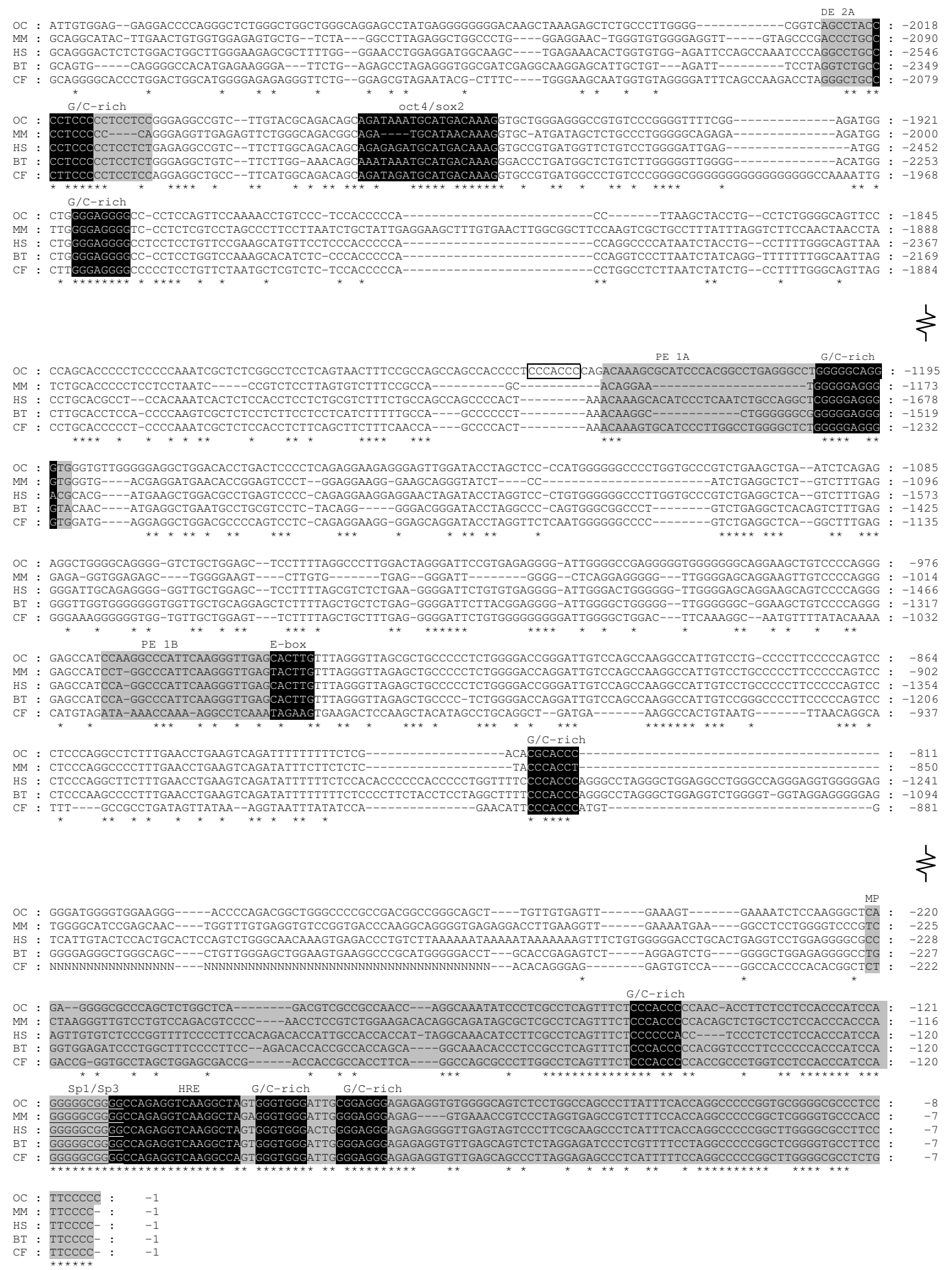

Figure I

Alignments of the rabbit $(O C)$ POU5FI regulatory regions with its mammalian orthologues. The region of distal enhancer, site 2A (DE 2A); proximal enhancer, sites IA and IB (PE IA, PE IB) and the minimal promoter (MP) are shaded in grey colour. The highly conserved GC-rich motifs like GGG(A/T)GGG, CCC(A/T)CCC and the putative transcription factor binding sites are shaded in black colour. A CCCACCC motif near PE IA present only in rabbit is rimmed; this motif partially overlaps a CCCTCCC motif (bolded). The Sp family binding site is underlined. Nucleotides have been numbered relative to the translation start site of the rabbit POU5FI gene. Oc, Oryctolagus cuniculus; Mm, Mus musculus; $\mathrm{Hs}$, Homo sapiens; Bt, Bos taurus, and Cf, Canis familiaris. 


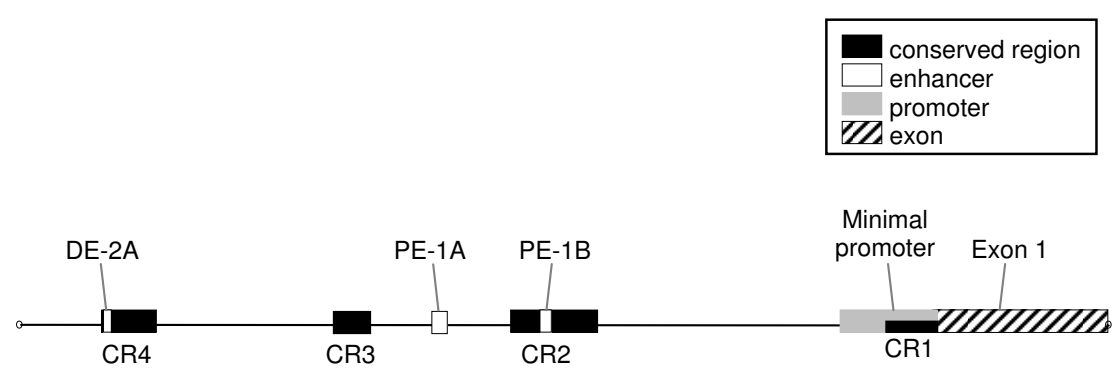

Figure 2

Organization of the POU5FI promoter region in rabbit (264I bp).

cence of non-transfected control R1 ESCs (Figure 3). Therefore, the rabbit POU5F1 regulatory region is capable to express in mouse ESC as a minimal promoter. The addition of CR2+CR3 regions did not increase the level of expression substantially compared to the CR1 fragment. However, when the CR4 region was co-transfected with the minimal promoter (CR1), the level of expression was increased more than two fold. Similarly, the expression was also two fold higher compared to that of the CR1 alone, when the full promoter region $[\mathrm{CR} 1+(\mathrm{CR} 2$ and CR3)+CR4] was transfected or the region of CR1+(CR2 and CR3) was co-transfected with the CR4. However, the intensity of the expression was significantly less compared to the ubiquitin promoter (B6U-3 ESC) or to the control pmaxGFP vector expression (Figure 3 ). When its expression was compared to the mouse POU5F1 minimal promoter (CR1) and distal enhancer-containing promoter region construct (Oct4-GiP) [21], the later exhibited a lower expression intensity in average (Figure 3 ).

\section{POU5FI expression in preimplantation stage embryos} The expression of rabbit POU5F1 gene was analyzed by quantitative real-time RT-PCR in preimplantation stage

Table 2: The homology (\%) between the nucleotide sequences of conserved regions and the complete upstream region

\begin{tabular}{lcccc}
\hline Conserved region of $\mathrm{Oc}$ & $\mathbf{M m}$ & $\mathbf{H s}$ & $\mathbf{B t}$ & $\mathbf{C f}$ \\
\hline CRI & 82.3 & $\mathbf{8 8 . 4}$ & 86.8 & 84.8 \\
CR2 & 92.0 & $\mathbf{9 3 . 9}$ & 90.7 & - \\
CR3 & 79.6 & $\mathbf{8 0 . 9}$ & 73.8 & 68.2 \\
CR4 & 67.6 & $\mathbf{8 3 . 6}$ & 78.0 & 67.1 \\
PE IA & 76.5 & $\mathbf{7 3 . 2}$ & 77.8 & $\mathbf{8 3 . 3}$ \\
PE IB & 96.0 & $\mathbf{9 6 . 4}$ & $\mathbf{9 6 . 4}$ & - \\
DE 2A & 87.5 & $\mathbf{9 5 . 0}$ & 90.0 & 85.7 \\
MP & $\mathbf{7 4 . 2}$ & $\mathbf{7 6 . 8}$ & 79.1 & $\mathbf{7 9 . 3}$ \\
5' region & 52.5 & $\mathbf{5 7 . 7}$ & 57.0 & 51.9 \\
\hline
\end{tabular}

Pairwise comparison method was used to compare the POU5FI regulatory regions of the rabbit and of the four mammalian species. The largest homologies of the regions are bolded; Oc, Oryctolagus cuniculus; Mm, Mus musculus; Hs, Homo sapiens; Bt, Bos taurus, and Cf, Canis familiaris; (-) no data. rabbit embryos, and compared with the mouse POU5F1 expression. In all examined stages the mRNA of POU5F1 was detectable in the embryos with various intensities. The mRNA was present in oocytes and zygotes at a higher level (Figure 4a and 4b), but the levels continuously decreased until the embryonic genome activation, which occurs between late 8 - to 16 -cell stages during rabbit preimplantation development $[18,22,23])$. Following the embryonic genome activation, the expression levels increased continuously until the blastocyst stage (Figure $4 \mathrm{~b})$. The POU5F1 transcript was also quantified in the isolated ICM and trophoblast portions of the rabbit blastocysts and the relative levels were compared taking the blastocyst transcript as calibrator. The comparison revealed that the POU5F1 gene was clearly expressed in both cell types but at a significantly higher $(\mathrm{p}<0.05)$ level in the ICM compared to the trophoblast cells (Figure 4c).

\section{Identification of pseudogenes}

BAC library screen was performed with primers oct4-435 and oct4-186 (Table 1) and BAC clones LBAB-304A07 and LBAB-779H10 were identified. Both clones contain a POU5F1-like sequence, and although they lack introns, they contain remnants of polyA tail flanked by direct repeats, all of the characteristics of retrotransposed pseudogenes [24,25]. Based on sequencing the flanking region, the two $\mathrm{BAC}$ clones were found to be identical, containing the same genomic region. Yet, the chromosomal localization of these BAC clones is unknown.

The cDNA of POU5F1 gene and its pseudogene share a 99\% overall sequence identity [see Additional file 1]. Sequence analysis revealed that there is an eight nucleotide deletion in the pseudogene in position $796 \mathrm{bp}$ from the initial ATG that causes a frameshift in the sequence. This results the encoding of a 162amino acid-long truncated protein instead of the 360 amino acid-long functional protein. This truncated form lacks the functional POU domain, but still has a $92 \%$ similarity on amino acid level until the frameshift caused STOP codon. The sequence of the pseudogene is referred as EU191070. 
A

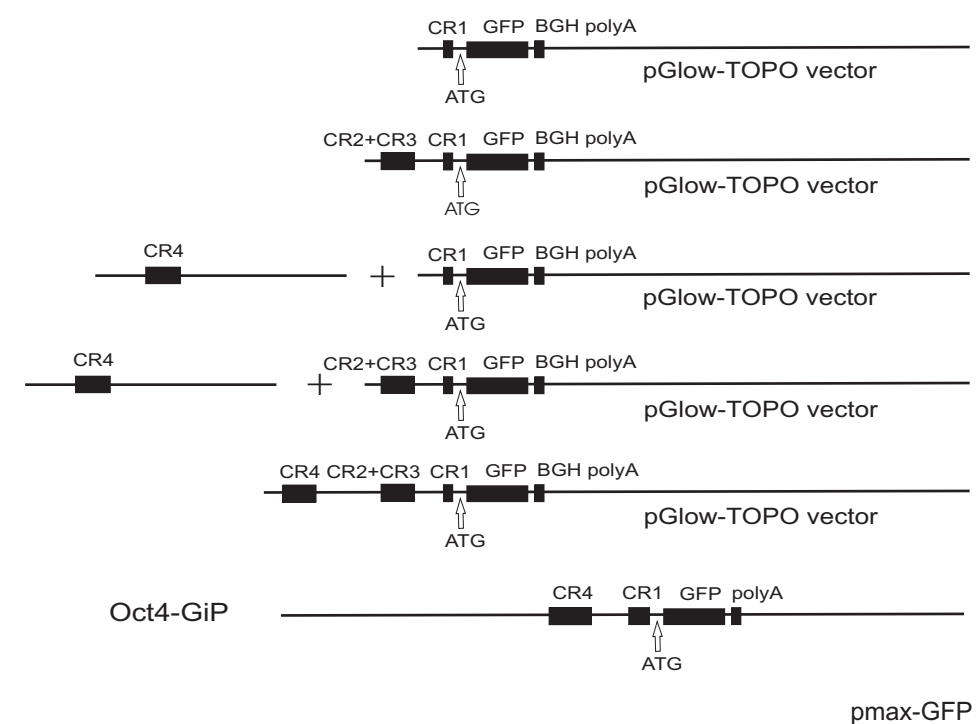

B6U-3
B

$\square$ Normalised Fluorescent Intensity

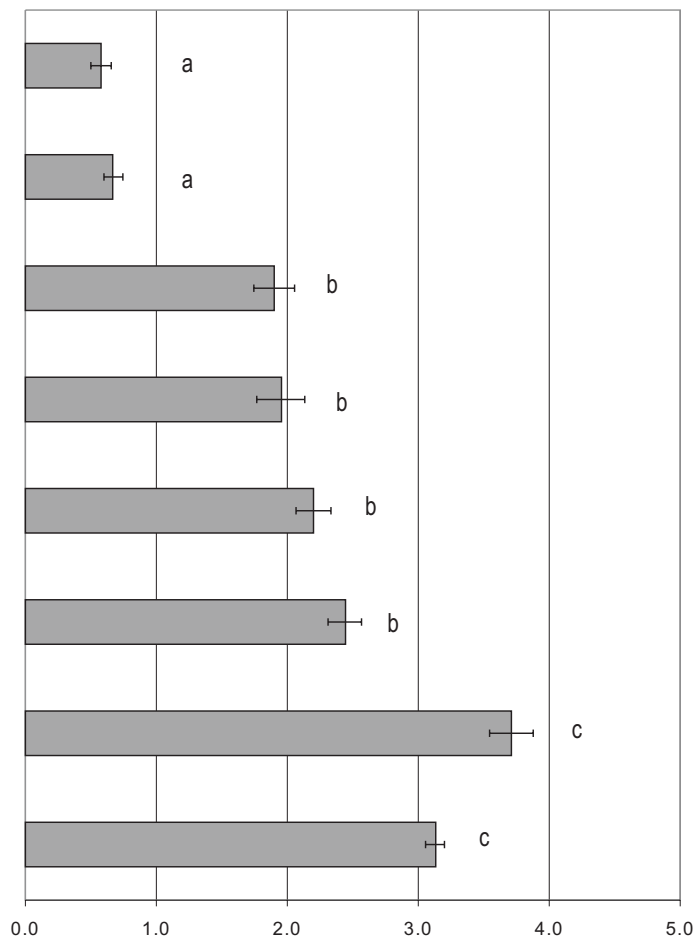

\section{Figure 3}

Expressional analysis of rabbit POU5FI promoter region in mouse ES cells. A. Schematic view of different constructs used in the assay. B. Fluorescent activity was measured 72 hours post-nucleofection. Data was normalised with the auto-fluorescence of untreated RI ESCs. CRI, the minimal promoter showed a weak level of basic expression in the mouse ESCs.

When the proximal enhancer fragment (CR2 and CR3) was part of the regulator region the expression showed no significant change. However, when the vector containing the distal enhancer region (CR4) was co-transfected either with the minimal promoter (CRI) or with the minimal promoter and proximal enhancers (CRI+(CR2 and CR3), the expression level increased significantly. While the entire regulatory region (CRI+(CR2 and CR3)+CR4) was transfected, the expression peaked to its highest level. If compared to the Oct4-GiP cells containing the mouse CR4+CRI region, no significant differences were found [20]. S.E. \pm values are marked on each column. Different letters mark significant differences between values $(P<0.05)$.

Furthermore, to test whether the pseudogene was retrotransposed back near to a functioning promoter, we examined its expression using pseudogene-specific primers in RT-qPCR experiment. The analysis showed that the pseudogene is not expressing at any preimplantation developmental-stages in rabbit [see Additional file 1].

\section{Discussion}

This is the first study describing the cloning and the analysis of the complete regulatory region of the rabbit POU5F1 gene. We have also cloned the rabbit Pou5f1 cDNA and analyzed the expression pattern in preimplantation-stage embryos. In addition, we identified a processed pseudogene, having a high degree of similarity.

Our results demonstrate that both the gene structure and the sequence of POU5F1 are extremely conserved among various species (rabbit and its murine, human, bovine and dog counterparts). As in other species, POU5F1 was mapped to the MHC region, and contained 5 exons with a longer first intron and 3' UTR. The putative protein sequence is almost identical with that of other species. This indicates the highly conserved role of POU5F1 in early vertebrate development.

In our study, the $2.2 \mathrm{~kb}$ fragment of the rabbit POU5F1 upstream region was isolated and aligned to its orthologues (Figure 1; GenBank: EU189135). Comparing the 5' region of human, bovine, mouse and $\operatorname{dog} P O U 5 F 1$ sequences to the rabbit, all the functionally important regions could be unquestionably defined within $3 \mathrm{~kb}$ upstream of its transcription start site. In comparison to the mouse, the rabbit sequence lacks large intersections between CR1 and CR2 regions, but the functional regions 
A

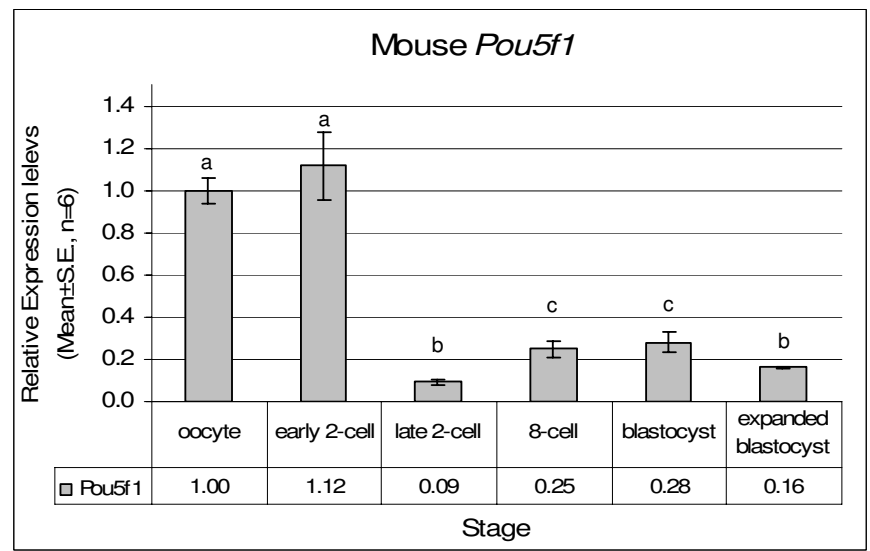

B

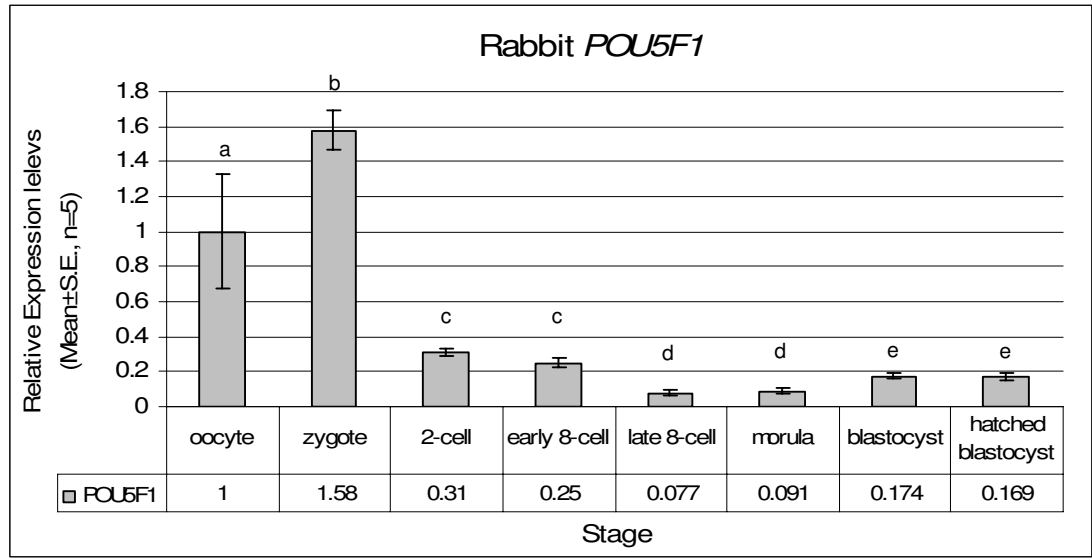

C

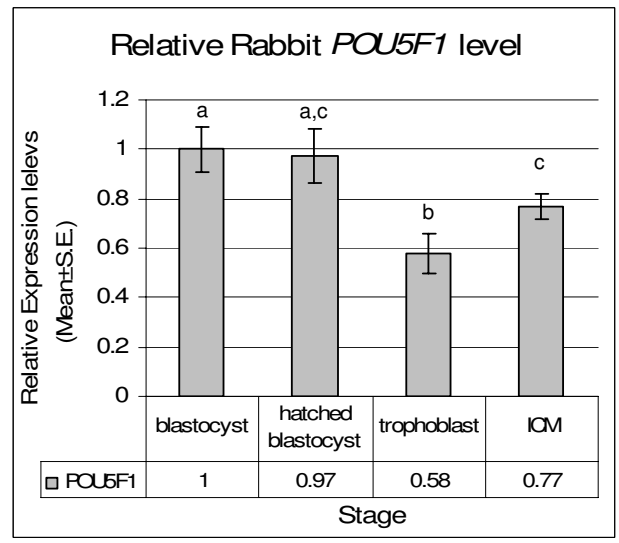

\section{Figure 4}

Oct4 expression in preimplantation stage rabbit embryos. A. Quantitative real time RT-PCR analysis of POU5FI expression in mouse and B. rabbit preimplantation stage embryos. C. Relative expression level of POU5FI in ICM and trophoblast portion of rabbit blastocyst. The mean values of gene expression of six individual samples and \pm S.E. are shown on the diagrams. For comparison of expression through developmental stages (B), the oocyte level was taken as calibrator, while for comparison of TE and ICM samples (C), the blastocyst level was taken as calibrator. Note the scale of the $y$-axis differs in the case of the two species. Different letters mark significant differences between values $(P<0.05)$. 
in all the four species were almost identical. Several conserved repetitive sequences, E-boxes, the binding site of Pem, Pax-3 and Sp1 transcription factors [26] were identified. Furthermore, the HRE binding site was also identified which was shown previously to be important in RAinduced POU5F1 down regulation. The newly identified CCC(A/T)CCC motifs that we have identified only in rabbit might gain importance when studying the differences of POU5F1 gene regulation in mammalian species.

The CR4 region is of particular interest for pluripotent stem cell research [21], because this region is responsible for the POU5F1 expression in ESCs [2]. Previously, the extended comparative sequence analysis of other mammals (pig, dog, rat) clearly showed three highly consensus sites inside the CR4 region [27]. In rabbit, all three sequences are identical; this suggests the functional significance and a highly conserved regulatory role in mammals. Using comparative sequence analysis we observed that the rabbit and the human POU5F1 regulatory regions share the greatest homology among the investigated four species.

Our functional assessment studies on mouse ESCs verified the sequence analysis results. In our experiments the rabbit CR4 region containing the promoter fragments showed the highest expression level in mouse ESCs. This suggests that the rabbit CR4 promoter region confer the same transcriptional regulation activity as the mouse CR4 sequence in mouse ESCs. Also, the rabbit construct showed no significant difference in expression intensity compared to the mouse POU5F1 promoter (Oct4-GiP).

The quantitative real-time RT-PCR showed that there is a high level of maternal origin POU5F1 mRNA in oocytes and zygotes, which decreased gradually until 8 to 16 -cell stage. The transiently reduced transcript levels increased continuously after the embryonic genome activation (Figure $4 \mathrm{~b})$. These data are in agreement with the measured (Figure 4a) and published gene expression patterns of mouse [28]. However, since the embryo genome activation in rabbit starts later than in mouse, a difference in the timing of endogenous POU5F1 expressions was detected between mouse and rabbit.

In mouse, the expression becomes confined to the ICM following the morula stage, up-regulated in the primitive ectoderm, and eventually becomes confined to primordial germ cells [2]. In rabbit, we found that the POU5F1 was expressed in both the trophoblast and the ICM at the mRNA level. In bovine, porcine, rhesus monkey and human preimplantation stage embryos the POU5F1 protein was also localized in both cell types [3-6]. In bovine the presence of POU5F1 protein in trophoblast cells might act as a suppressor of extraembryonic lineage-spe- cific gene expression during the preimplantation development which allows an extensive proliferation of the trophoblast before the implantation $[4,29]$. These results indicate that the restriction of expression in blastocyst stage is species-specific [3].

Finally, we have identified a processed, retrotransposed pseudogene of the rabbit POU5F1. Retrotransposed genes are generated from mRNA and they integrate back to the genome after reverse transcription. Due to this process, these kinds of pseudogenes usually lack a functioning promoter, or endure some modification, which make them unable to code the functional or full-length proteins. Here we confirmed that the newly identified rabbit POU5F1 pseudogene was not expressed during rabbit preimplantation development. Further studies will be needed to clarify its expression in further developmental stages and in differentiated tissues as some pseudogenes are known to possess certain regulatory roles [30-32]. Bioinformatics analysis revealed that retrotransposition frequency of ESC-specific genes appears far to exceed that of non-ESC specific genes, and multiple highly homologous pseudogenes likely exist for all of the ESC-specific genes [33,34]. This is a characteristic of human [35] and also of mouse $[1,36,37]$. It is not clear yet whether this abundant presence of pluripotency pseudogenes in mouse and human would be also an indication of unknown functions. In human the POU5F1P1 pseudogene encodes a putative protein similar to POU5F1 isoform 1, which is localized close to the amplified region of a variety of human malignancies [38]. Recent reports on human POU5F1 pseudogenes suggested - especially in somatic cells, tissue-specific stem cells, and non-germ cell tumours - that some re-evaluation of expression data on POU5F1 might be needed due to the use of primers which cannot distinguish pseudogenes from the coding one [39-41]. In other species including the mouse and rabbit - the functional relevance of pseudogenes of POU5F1 is still uncovered.

\section{Conclusion}

This study provides the first comprehensive analysis of rabbit POU5F1 regulatory domains. Detailed sequence analysis of the isolated rabbit $P O U 5 F 1$ promoter revealed high sequence conservation in the identified enhancer domains. The strong conservation of regulatory domain sequences shows the importance of the control of POU5F1 expression in early mammalian development. We have shown that the highest homology of enhancers can be identified between human and rabbit. This may increase the importance to use the rabbit as a comparative functional genomics tool for human medical research.

\section{Methods}

All chemicals, unless otherwise stated, were purchased from Invitrogen Inc. (Carlsbad, California, USA). 
The animal experiments were executed in full compliance with European and Hungarian laws and regulations, and were approved by the Agricultural Biotechnology Center, Animal Experimentation Committee, Gödöllö, Hungary.

\section{Rabbit BAC library}

From a rabbit genomic BAC library [19] four BAC clones were isolated (LBAB-841A3; LBAB-85810; LBAB-304A07 and LBAB-779H10). The clones are stored at the INRA resource centre [42]. The library screening was performed as reported previously [19].

\section{Cloning and sequencing}

The obtained PCR fragments were cloned into pCR2.1TOPO vector. BAC clones and plasmid DNAs were purified by QIAGEN Plasmid Maxi Kit and QIAprep Spin Miniprep Kit, respectively (QIAGEN). Sequencing was performed in the $\mathrm{ABC}$ Sequencing Laboratory with Applied Biosystems BigDye v3.1 Ready Reaction Terminator Cycle Sequencing Kit (ABI) using the ABI PRISM 3100 Genetic Analyser automated nucleotide sequencer.

The genomic sequence of Oryctolagus cuniculus 5' regulatory region of POU5F1 gene is deposited at the GenBank under accession number [EU189135].

\section{Comparative genomics}

The POU5F1 sequence was submitted and referred as [GenBank: EF062856] for cDNA, and as [GenBank: EF194086] for genomic sequence. For multiple alignments the following genomic, cDNA and protein sequences were used: [GenBank: NT 007592.14], [GenBank: NM 002701.4], [GenBank: NP 002692.2] for human; [GenBank: MGI_101893], [GenBank: NM 013633.2], [GenBank: NP 038661.2] for mouse; and [GenBank: NW 001494164.1], [GenBank: NM 174580.1], [GenBank: NP 777005.1] for bovine, respectively.

For the comparative analysis the POU5F1 5' upstream sequences of mouse [GenBank: NT 039649.7], human [GenBank: NT 007592.14g] bovine [GenBankAF022986] and dog [GenBank: NC 006594.2] sequences were aligned by using ClustalW2 program [43]. Pairwise comparison of nucleotide sequences was performed on EMBOSS Pairwise Alignment Algorithms program [44].

\section{RACE-PCR}

Rapid Amplification of cDNA Ends (RACE) PCR was performed according to the manufacturer's instruction. As outer primers oct4-5UTR and oligo(dT) primers were used, while oct4-435 and oct4-186 primers were applied as inner, gene-specific primers (Table 1).

\section{Sample materials}

All samples were isolated from Hycole Hybrid rabbits. Oocytes were collected 16 hours post-hCG injection, while one-cell stage embryos were collected 18 hours post-hCG injection from adult female rabbits. Zygotes were cultivated in EBSS media [45] at $38.5^{\circ} \mathrm{C}$ under $5 \%$ $\mathrm{CO}_{2}$ in air. After removing the zona pellucida with Pronase (Sigma), samples were collected in each developmental stage and kept frozen at $-86^{\circ} \mathrm{C}$ until use. ICM and trophoblast samples from blastocyst were separated using the XYClone laser system (Hamilton Thorne Biosciences) [46]. Briefly, a blastocyst held by two large bore capillaries at the trophoblast region and at the ICM region, respectively, was gently pulled apart while exposed to laser pulses at the area of the trophoblast adjacent to the ICM. When the laser pulses cut through the cells, the two separated parts of the blastocyst were stored separately for further analyses. Due to the visually controlled nature of the procedure, the trophoblast sample is guaranteed to be ICM-cell free, however, the ICM sample might contain a small number of trophoblast cells. Mouse oocytes and in vivo embryo samples were collected as described earlier [47].

\section{Functional analysis of the POU5FI promoter}

The conserved regions of the POU5F1 promoter were identified by multiple sequence alignments, amplified with PCR (Table 1) and subcloned into the pGlow TOPO ${ }^{\circledR}$ TA Expression Kit, containing the GFP reporter gene. The start codon of translation was mutated with PCR-based ATG-mutagenesis (Table 1).

The constructs were nucleofected into mouse R1 ESC by using the AMAXA Nucleofector System and Mouse ES cell Nucleofector Kit (Amaxa Biosystems). Electroporation was carried out based on the manufacturer's protocol using program no. A23. Briefly, $5 \times 10^{6}$ cells were used for the nucleofection and about $5 \mu \mathrm{g}$ of plasmid DNA were applied, after copy number normalization of the different constructs. Neomycin selection was started 24 hours postnucleofection by applying $400 \mu \mathrm{g} / \mathrm{ml} \mathrm{G418} \mathrm{on} \mathrm{the} \mathrm{cul-}$ tures. For transfection control the Amaxa Nucleofector Kit control vector pmaxGFP was used.

The R1 ESC line [48] (provided by Dr. Andras Nagy; Samuel Lunenfeld Research Institute, Toronto, Canada) was cultured using standard protocols [49]. Oct4-GiP transgenic mouse ESC line, expressing the EGFP reporter gene under the control of mouse POU5F1 [CR4+CR1] promoter region was kindly provided by Dr. Austin Smith (University of Edinburgh's Centre for Genome Research, Edinburgh, UK) [21]. The transgenic ubiquitin promoterGFP expressing ESC line (B6U 3) was isolated from C57BL/6-Tg(UBC-GFP)30Scha/J transgenic mice (Stock 
Number: 004353; The Jackson Laboratory) in our laboratory (unpublished data).

\section{Fluorimetric assay}

For GFP assays, cells were harvested at 72 hours posttransfection and the fluorescent intensity was measured using the Perkin-Elmer LS-50B Luminescence Spectrophotometer (PerkinElmer Life and Analytical Sciences Inc.; excitation: $375 \mathrm{~nm}$, detection: $510 \mathrm{~nm}$ ). Fluorescence was corrected for background activity shown by cells transfected with the pGlow-TOPO $^{\circledast}$ vector alone. Cell number variation between individual experiments was corrected measuring the cell protein content (Bio-Rad DC Protein Assay system, BioRad Laboratories).

Primer design and quantitative real-time $R T-P C R$ analysis To design POU5F1 pseudogene-specific primers, we initially performed a BLASTn [50] search to reveal any rabbit POU5F1 pseudogene sequence up to date. This led to the only pseudogene sequence referred EU191070. Based on the sequence alignment of the POU5F1 mRNA and its pseudogene [see Additional file 1], we designed a primer to the eight nucleotide deletion region, to avoid amplification of the POU5F1 mRNA (Table 1).

The procedures of RNA isolation and cDNA synthesis were done as described in our earlier work [51]. Briefly, the mRNA was extracted from individual oocytes and embryos by Dynabeads ${ }^{\circledast}$ mRNA Direct Micro Kit according to the manufacturer's instructions. DNase treatment (Ambion-ABI) was applied on all RNA samples before cDNA synthesis. Genomic DNA was isolated from rabbit skin by phenol-chlorophorm extraction according to the standard methodology. Complementary DNA synthesis was performed with MMLV Reverse Transcriptase and oligodT primers, using the manufacturer's protocol.

Real-time PCR was performed in Rotor-Gene 3000 Realtime PCR Cycler (Corbett Research, Mortlake, Australia). The reaction mixture consisted of SYBR $^{\circledR}$ Green JumpStart $^{\mathrm{TM}}$ Taq ReadyMix ${ }^{\mathrm{TM}}$ (Sigma), $300 \mathrm{nM}$ of each primer (Table 1), and cDNA of 0.10 embryo equivalent in a final volume of $25 \mu \mathrm{l}$.

The reaction conditions were template denaturation and polymerase activation at $95^{\circ} \mathrm{C}$ for 2 min followed by 45 cycles of $95^{\circ} \mathrm{C}$ denaturation for $15 \mathrm{sec}, 60^{\circ} \mathrm{C}$ annealing and extension for $45 \mathrm{sec}$ with a single fluorescence measurement at each cycle. When the reaction was completed, melting curves were plotted to confirm the specificity of the product. Data were normalized based on the sets of reference genes (H2afz, Hprt1 and Ywhaz) [18]. Similar normalization procedures during mouse Pou5f1 transcript quantification were carried out using sets of mouse reference genes are published previously [47].

\section{Statistical analysis}

Data were analyzed using the Chi-square test. P-values less than 0.05 were considered statistically significant.

\section{Authors' contributions}

JK jointly conceived the studies and performed the experimental design, carried out subcloning of promoter regions, performed the functional promoter test in mouse ESCs, and wrote the manuscript. KK carried out the molecular genetic studies and participated in the sequence alignment. ZP prepared in vivo and in vitro rabbit embryos for the experiments. SM carried out the real-time RT-PCRs analyses, and participated in manuscript preparation. CRG carried out the rabbit BAC library screens and provided the clones. ZT participated in cDNA cloning from blastocyst stage rabbit embryos. IB participated in computational analysis of DNA sequences, pseudogene specific primer design, and qPCRs. ABG participated in primer design, data analyses, and performed statistical tests. KT contributed to the experimental manipulations, MKP gave constructive comments on the study design and drafting the manuscript, AD conceived the studies, supervised the study design, execution, analysis, and approved the final version. All authors read and approved the manuscript.

\section{Additional material}

\section{Additional file 1}

Pseudogene of rabbit POU5F1. The data provided represent the alignment of rabbit cDNA and pseudogene sequence, and the expression of the pseudogene in preimplantation stage rabbit embryos.

Click here for file

[http://www.biomedcentral.com/content/supplementary/14712199-10-88-S1.pdf]

\section{Acknowledgements}

The authors would like to thank Mrs Hajnalka Csákány Tolnainé for her excellent technical assistance during the experiment and for Dr. Claudia Stanca for her advice and help with the preimplantation-stage rabbit embryo manipulations and expression studies. This research was supported by Wellcome Trust (Grant No. 070246); OTKA T046I7I, OMFB-01220/ 2006, NKTH-OTKA FP7 Mobility "HUMAN-MB08C-80205", HungarianChinese NKTH TET (No. CN-56/2007) projects; NKTH/ANR TET Franco-Hungarian Bilateral Scientific and Technological Collaborative Project "Plurabit", NKTH/KPI Kozma F. TUDAS-I-2006-0005, and European Union FP6 CLONET (MRTN-CT-2006-035468) and MED-RAT (LSHG-CT-2006-518240).

\section{References}

I. Scholer HR, Ruppert S, Suzuki N, Chowdhury K, Gruss P: New type of POU domain in germ line-specific protein Oct-4. Nature 1990, 344:435-9.

2. Yeom YI, Fuhrmann G, Ovitt CE, Brehm A, Ohbo K, Gross M, Hubner K, Scholer HR: Germline regulatory element of Oct-4 specific for the totipotent cycle of embryonal cells. Development 1996, I 22:881-94. 
3. Kirchhof N, Carnwath JW, Lemme E, Anastassiadis K, Scholer H, Niemann $\mathrm{H}$ : Expression pattern of Oct-4 in preimplantation embryos of different species. Biol Reprod 2000, 63: 1698-705.

4. van Eijk MJ, van Rooijen MA, Modina S, Scesi L, Folkers G, van Tol HT, Bevers MM, Fisher SR, Lewin HA, Rakacolli D, et al:: Molecular cloning, genetic mapping, and developmental expression of bovine POU5FI. Biol Reprod 1999, 60:1093-103.

5. Cauffman G, Velde H Van de, Liebaers I, Van Steirteghem A: Oct-4 mRNA and protein expression during human preimplantation development. Mol Hum Reprod 2005, I I: | 73-8 I.

6. Mitalipov SM, Kuo HC, Hennebold JD, Wolf DP: Oct-4 expression in pluripotent cells of the rhesus monkey. Biol Reprod 2003, 69:1785-92.

7. Boiani M, Scholer HR: Regulatory networks in embryo-derived pluripotent stem cells. Nat Rev Mol Cell Biol 2005, 6:872-84.

8. Cauffman G, Liebaers I, Van Steirteghem A, Velde H Van de: POU5FI isoforms show different expression patterns in human embryonic stem cells and preimplantation embryos. Stem Cells 2006, 24:2685-9I.

9. Boyer LA, Lee TI, Cole MF, Johnstone SE, Levine SS, Zucker JP, Guenther MG, Kumar RM, Murray HL, Jenner RG, et al.: Core transcriptional regulatory circuitry in human embryonic stem cells. Cell 2005, I 22:947-56.

10. Pesce M, Anastassiadis K, Scholer HR: Oct-4: lessons of totipotency from embryonic stem cells. Cells Tissues Organs 1999, 165:|44-52.

II. Nordhoff V, Hubner K, Bauer A, Orlova I, Malapetsa A, Scholer HR: Comparative analysis of human, bovine, and murine Oct-4 upstream promoter sequences. Mamm Genome 2001, 1 2:309-17.

12. Ovitt CE, Scholer HR: The molecular biology of Oct-4 in the early mouse embryo. Mol Hum Reprod 1998, 4:|02I-3I.

13. Fang ZF, Gai H, Huang YZ, Li SG, Chen XJ, Shi JJ, Wu L, Liu A, Xu P Sheng HZ: Rabbit embryonic stem cell lines derived from fertilized, parthenogenetic or somatic cell nuclear transfer embryos. Exp Cell Res 2006, 3 I 2:3669-82

14. Wang S, Tang X, Niu Y, Chen H, Li B, Li T, Zhang X, Hu Z, Zhou Q, Ji W: Generation and characterization of rabbit embryonic stem cells. Stem Cells 2007, 25:481-9.

15. Meng Q, Polgar Z, Liu J, Dinnyes A: Live birth of somatic cellcloned rabbits following trichostatin $A$ treatment and cotransfer of parthenogenetic embryos. Cloning Stem Cells 2009, I I:203-208.

16. Chesne P, Adenot PG, Viglietta C, Baratte M, Boulanger L, Renard JP: Cloned rabbits produced by nuclear transfer from adult somatic cells. Nat Biotechnol 2002, 20:366-9.

17. Shi J, Cai DH, Chen XJ, Sheng HZ: Cloning and characterization of the rabbit POU5FI gene. DNA Seq 2008, 19:56-6I.

18. Mamo S, Gal AB, Polgar Z, Dinnyes A: Expression profiles of the pluripotency marker gene POU5FI and validation of reference genes in rabbit oocytes and preimplantation stage embryos. BMC Mol Biol 2008, 9:67.

19. Rogel-Gaillard C, Piumi F, Billault A, Bourgeaux N, Save JC, Urien C, Salmon J, Chardon P: Construction of a rabbit bacterial artificial chromosome (BAC) library: application to the mapping of the major histocompatibility complex to position I2q.I.I. Mamm Genome 200I, I 2:253-5.

20. Yeom YI, Ha HS, Balling R, Scholer HR, Artzt K: Structure, expression and chromosomal location of the Oct-4 gene. Mech Dev 1991, 35:171-9.

21. Hubner K, Fuhrmann G, Christenson LK, Kehler J, Reinbold R, De La Fuente R, Wood J, Strauss JF 3rd, Boiani M, Scholer HR: Derivation of oocytes from mouse embryonic stem cells. Science 2003, 300: $|25|-6$

22. Brunet-Simon A, Henrion G, Renard JP, Duranthon V: Onset of zygotic transcription and maternal transcript legacy in the rabbit embryo. Mol Reprod Dev 200I, 58:127-36.

23. Leandri RD, Archilla C, Bui LC, Peynot N, Liu Z, Cabau C, Chastellier $A$, Renard JP, Duranthon V: Revealing the dynamics of gene expression during embryonic genome activation and first differentiation in the rabbit embryo with a dedicated array screening. Physiol Genomics 2009, 36:98-II3.

24. Mighell AJ, Smith NR, Robinson PA, Markham AF: Vertebrate pseudogenes. FEBS Lett 2000, 468:109-14.

25. Vanin EF: Processed pseudogenes: characteristics and evolution. Annu Rev Genet 1985, 19:253-72.
26. Pugh BF, Tjian R: Transcription from a TATA-less promoter requires a multisubunit TFIID complex. Genes Dev 1991, 5:1935-45.

27. Chew JL, Loh YH, Zhang W, Chen X, Tam WL, Yeap LS, Li P, Ang YS Lim B, Robson $\mathrm{P}$, et al.: Reciprocal transcriptional regulation of Pou5fl and Sox 2 via the Oct4/Sox 2 complex in embryonic stem cells. Mol Cell Biol 2005, 25:603I-46.

28. Pan GJ, Chang ZY, Scholer HR, Pei D: Stem cell pluripotency and transcription factor Oct4. Cell Res 2002, I 2:32I-9.

29. Kurosaka S, Eckardt S, McLaughlin KJ: Pluripotent lineage definition in bovine embryos by Oct4 transcript localization. Biol Reprod 2004, 71: I578-82

30. Bellingham J, Gregory-Evans K, Fox MF, Gregory-Evans CY: Gene structure and tissue expression of human selenoprotein $W$, SEPWI, and identification of a retroprocessed pseudogene, SEPWIP. Biochim Biophys Acta 2003, I 627:|40-6.

31. Hirotsune S, Yoshida N, Chen A, Garrett L, Sugiyama F, Takahashi S, Yagami K, Wynshaw-Boris A, Yoshiki A: An expressed pseudogene regulates the messenger-RNA stability of its homologous coding gene. Nature 2003, 423:91-6.

32. Korneev SA, Park JH, O'Shea M: Neuronal expression of neural nitric oxide synthase (nNOS) protein is suppressed by an antisense RNA transcribed from an NOS pseudogene. I Neurosci 1999, I9:77| I-20.

33. Elliman SJ, Wu I, Kemp DM: Adult tissue-specific expression of a Dppa3-derived retrogene represents a postnatal transcript of pluripotent cell origin. J Biol Chem 2006, 28 I: I 6-9.

34. Pain D, Chirn GW, Strassel C, Kemp DM: Multiple retropseudogenes from pluripotent cell-specific gene expression indicates a potential signature for novel gene identification. J Biol Chem 2005, 280:6265-8.

35. Takeda J, Seino S, Bell Gl: Human Oct3 gene family: cDNA sequences, alternative splicing, gene organization, chromosomal location, and expression at low levels in adult tissues. Nucleic Acids Res 1992, 20:46I 3-20.

36. Okamoto K, Okazawa H, Okuda A, Sakai M, Muramatsu M, Hamada $\mathrm{H}$ : A novel octamer binding transcription factor is differentially expressed in mouse embryonic cells. Cell 1990, 60:461-72.

37. Okazawa H, Okamoto K, Ishino F, Ishino-Kaneko T, Takeda S, Toyoda $Y$, Muramatsu M, Hamada $H$ : The oct3 gene, a gene for an embryonic transcription factor, is controlled by a retinoic acid repressible enhancer. Embo J 1991, 10:2997-3005

38. Panagopoulos I, Moller E, Collin A, Mertens F: The POU5FIPI pseudogene encodes a putative protein similar to POU5FI isoform I. Oncol Rep 2008, 20:1029-33.

39. Liedtke S, Enczmann J, Waclawczyk S, Wernet P, Kogler G: Oct4 and its pseudogenes confuse stem cell research. Cell Stem Cell 2007, I :364-6.

40. Liedtke S, Stephan M, Kögler G: Oct4 expression revisited: potential pitfalls for data misinterpretation in stem cell research. Biological Chemistry 2008, 389:845-850.

4I. Monk M, Hitchins M, Hawes S: Differential expression of the embryo/cancer gene ECSA(DPPA2), the cancer/testis gene BORIS and the pluripotency structural gene OCT4, in human preimplantation development. Mol Hum Reprod 2008 , I 4:347-55.

42. GADIE Biologicals Resources Centre [http://wwwcrb.jouy.inra.fr/BRC/libraries-e.htm]

43. ClustalW2 program [http://www.ebi.ac.uk/Tools/clustalw2/]

44. EMBOSS Pairwise Alignment Algorithms program [http:// www.ebi.ac.uk/Tools/emboss/align]

45. Mitalipov SM, White KL, Farrar VR, Morrey J, Reed WA: Development of nuclear transfer and parthenogenetic rabbit embryos activated with inositol 1,4,5-trisphosphate. Biol Reprod 1999, 60:821-7.

46. Tanaka N, Takeuchi T, Neri QV, Sills ES, Palermo GD: Laserassisted blastocyst dissection and subsequent cultivation of embryonic stem cells in a serum/cell free culture system: applications and preliminary results in a murine model. Transl Med 2006, 4:20.

47. Mamo S, Gal AB, Bodo S, Dinnyes A: Quantitative evaluation and selection of reference genes in mouse oocytes and embryos cultured in vivo and in vitro. BMC Dev Biol 2007, 7:I4.

48. Nagy A, Rossant J, Nagy R, Abramow-Newerly W, Roder JC: Derivation of completely cell culture-derived mice from early- 
passage embryonic stem cells. Proc Natl Acad Sci USA 1993, 90:8424-8.

49. Nagy A: Manipulating the mouse embryo: a laboratory manual. 3rd edition. Cold Spring Harbor, N.Y.: Cold Spring Harbor Laboratory Press; 2003.

50. BLASTn program [http://blast.ncbi.nlm.nih.gov/Blast.cgi]

5I. Gal AB, Carnwath JW, Dinnyes A, Herrmann D, Niemann H, Wrenzycki C: Comparison of real-time polymerase chain reaction and end-point polymerase chain reaction for the analysis of gene expression in preimplantation embryos. Reprod Fertil Dev 2006, 18:365-7I.

Publish with Bio Med Central and every scientist can read your work free of charge

"BioMed Central will be the most significant development for disseminating the results of biomedical research in our lifetime. "

Sir Paul Nurse, Cancer Research UK

Your research papers will be:

- available free of charge to the entire biomedical community

- peer reviewed and published immediately upon acceptance

- cited in PubMed and archived on PubMed Central

- yours - you keep the copyright

Submit your manuscript here:

http://www.biomedcentral.com/info/publishing_adv.asp
BioMedcentral 